American astronomers to take advantage of these facilities. To meet the challenge, two traditional Mexican programs (Instituto de Astronomia-UNAM and Instituto Nacional de Astrofisica, Optica y Electronica-INAOE) are updating their graduate programs. Similarly, the Departamento de Astronomía de la Universidad de Guanajuato is joining physicists in the first undergraduate program in México in physics and engineering with an option in astrophysics. This will prepare students for industry, academia or national laboratories, either in physics or astronomy. Jobs in academia have been scarce; many students had to give up their goals after one or two postdoctoral positions. Graduate and undergraduate programs must adjust, by broadening the scope of present programs so that students are better prepared for other job opportunities. We present a B.Sc. program designed by astronomers and physicists to try to address some of these concerns and to prepare the students for either continuing with graduate studies or finding employment in an ever-changing job market. (Co-author is Victor Migenes, Guamajato, México.)

\title{
Astronomy in Romanian Universities
}

Mihail Barbosu, Faculty of Mathematics, Babes-Bolyai University, RO 3400 Cluj-Napoca, Romania

In this work we present characteristics of the Romanian higher education related to the study of Astronomy. In spite of Romanian economic problems, opportunities for Bachelor's degree, Master's degree (at "Babes-Bolyai" University of Cluj-Napoca) and Ph.D. degree are provided for students enrolled in the Faculties of Mathematics or Physics. General regulations, description of courses, research resources and job opportunities are also described and discussed in this paper.

\section{Astronomy Education in Thailand}

\section{Busaba Hutawarakorn et al., National Electronics and Computer Technology Center, Thailand}

Thailand is one of the developing countries which tries to advance its economy, technology and science. Education in astronomy is considered a supporting factor; astronomy is a basic science from which the young generation can learn to understand and to conserve mother nature and at the same time develop analytical thinking. The poster reports the present developments in astronomical education in Thailand which includes (1) current astronomy education in school and university; (2) educational activities outside school; (3) development of programs for teaching astronomy in school (including teacher training); (4) the access of educational resources via internet. Proposals for future development and collaborations will be presented and discussed. (Co-authors are B. Soonthornthum and T. Kirdkao.) 